\title{
SHARP INEQUALITIES INVOLVING NEUMAN MEANS OF THE SECOND KIND
}

\section{WeI-MaO Qian, Zhi-Hua ShaO AND Yu-Ming Chu}

Abstract. In the article, we present several sharp inequalities involving the Neuman means of the second kind, and the logarithmic, Seiffert, arithmetic, Neuman-Sándor, quadratic and contraharmonic means.

Mathematics subject classification (2010): 26E60.

Keywords and phrases: Neuman means of the second kind, logarithmic mean, Seiffert mean, quadratic mean, Neuman-Sándor mean, contraharmonic mean.

\section{REFERENCES}

[1] B. C. Carlson, Special Functions of Applied Mathematics, Academic Press, New York, 1977.

[2] B. C. CARLSON AND J. L. GUSTAFSON, Asymptotic approximations for symmetric elliptic integrals, SIAM J. Math. Anal., 1994, 25 (2): 288-303.

[3] E. Neuman And J. SÁndor, On the Schwab-Borchardt mean, Math. Pannon., 2003, 14 (2): $253-$ 266.

[4] E. Neuman And J. SÁndor, On the Schwab-Borchardt mean II, Math. Pannon., 2006, 17 (1): 4959.

[5] E. Neuman, Inequalities for the Schwab-Boorchardt mean and their applications, J. Math. Inequal., 2011, 5 (4): 601-609.

[6] B. C. CARLSON, Algorithms involving arithmetic and geometric means, Amer. Math. Monthly, 1971, 78: 496-505.

[7] J. L. BREnNer AND B. C. CARLson, Homogeneous mean values: weights and asymptotics, J. Math. Anal. Appl., 1987, 123 (1): 265-280.

[8] H. LiU AND X.-J. Meng, The optimal convex combination bounds for Seiffert's mean, J. Inequal. Appl., 2011, Article ID 686834, 9 pages.

[9] W.-D. JIANG AND F. QI, Some sharp inequalities involving Seiffert and other means and their concise proofs, Math. Inequal. Appl., 2012, 15 (4): 1007-1017.

[10] W.-D. JIANG, Some sharp inequalities involving reciprocals of the Seiffert and other means, J. Math. Inequal., 2012, 6 (4): 593-599.

[11] E. Neuman, A note on a certain bivariate mean, J. Math. Inequal., 2012, 6 (4): 637-643.

[12] E. Neuman, On one-parameter family of bivariate means, Aequations Math., 2012, 83 (1-2): 191197.

[13] E. Neuman, A one-parameter family of bivariate means, J. Math. Inequal., 2013, 7 (3): 399-412.

[14] E. Neuman, Inequalities involving certain bivariate means II, J. Inequal. Spec. Funct., 2013, 4 (4): $12-20$.

[15] E. Neuman, Sharp inequalities involving Neuman-Sándor and logarithmic means, J. Math. Inequal., 2013, 7 (3): 413-419.

[16] E. Neuman And J. SÁNDOR, Bounds for the quotients of differences of certain bivariate means, Adv. Stud. Contemp. Math., 2013, 23 (1): 61-67.

[17] Y.-M. ChU, M.-K. WANG AND Z.-K. WANG, Best possible inequalities among harmonic, geometric, logarithmic and Seiffert means, Math. Inequal. Appl., 2012, 15 (2): 415-433.

[18] W.-M. QIAN AND Y.-M. CHU, Optimal bounds for Neuman means in terms of geometric, arithmetic and quadratic means, J. Inequal. Appl., 2014, 2014: 175, 13 pages. 
[19] Z.-H. YAnG, Y.-Q. Song AND Y.-M. CHU, Monotonicity of the ratio of the power and second Seiffert means with applications, Abstr. Appl. Anal., 2014, Article ID 840130, 4 pages.

[20] Y.-M. ChU, H. WANG AND T.-H. ZHAO, Sharp bounds for Neuman mean in terms of the quadratic and second Seiffert means, J. Inequal. Appl., 2014, 2014: 299, 14 pages.

[21] Y.-M. ChU AND W.-M. Qian, Refinements of bounds for Neuman means, Abstr. Appl. Anal., 2014, Article ID 354132, 8 pages.

[22] E. Neuman, On some means derived from the Schwab-Borchardt mean, J. Math. Inequal., 2014, 8 (1): 171-183.

[23] E. Neuman, On some means derived from the Schwab-Borchardt mean II, J. Math. Inequal., 2014, 8 (2): 359-368.

[24] E. Neuman, On a new bivariate mean, Aequat. Math., 2014, 88 (3): 277-289.

[25] S.-B. Chen, Z.-Y. He, Y.-M. ChU, Y.-Q. Song AND X.-J. TAO, Note on certain inequalities for Neuman means, J. Inequal. Appl., 2014, 2014: 370, 10 pages.

[26] Z.-J. GuO, Y.-M. CHU, Y.-Q. SONG AND X.-J. TAO, Sharp bounds for Neuman means by harmonic, arithmetic, and contraharmonic means, Abstr. Appl. Anal., 2014, Article ID 914242, 8 pages.

[27] Y. ZhANG, Y.-M. ChU AND Y.-L. JiAng, Sharp geometric mean bounds for Neuman means, Abstr. Appl. Anal., 2014, Article ID 949815, 6 pages.

[28] G. D. Anderson, M. K. Vamanamurthy and M. Vuorinen, Conformal Invariants, Inequalities, and Quasiconformal Maps, John Wiley \& Sons, New York, 1977.

[29] G. D. Anderson, S.-L. Qiu, M. K. Vamanamurthy and M. Vuorinen, Generalized elliptic integrals and modular equations, Pacific J. Math., 1997, 192 (1): 1-37.

[30] S. SimiĆ AND M. VuORINEN, Landen inequalities for zero-balanced hypergeometric functions, Abstr. Appl. Anal., 2012, Article ID 932061, 11 pages. 